\title{
A PSYCHOPATHOLOGICAL CHARACTERIZATION OF A SAMPLE OF FIRST EPISODE PSYCHOSIS INPATIENTS
}

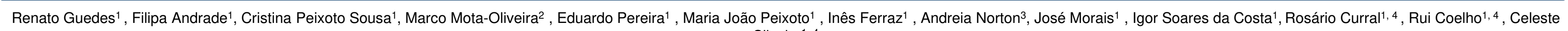
Silveira1, 4

\author{
Psychiatry Service, São João University Hospital Center, Porto, Portugal \\ 2 Department of Psychiatry and Mental Health, University Hospital Center of Algarve, Faro, Portuga \\ Magalhães Lemos Hospital, Porto, Portugal \\ ${ }^{4}$ Department of Clinical Neurosciences and Mental Health, Faculty of Medicine, University of Porto, Portugal
}

Introduction

Objectives

\section{Methods}

\section{Results}

In first episode psychosis (FEP), the term psychosis is merely descriptive and doesn't allow for any assumptions regarding etiology or prognosis. Given the heterogeneity of psychopathology in FEP there is great uncertainty regarding the establishment of an accurate diagnosis.

\section{Psychopathological characterization and comparison between diagnostic groups of inpatients with FEP.}

Retrospective observational study including patients with FEP admitted to the inpatient unit of the Psychiatry Service of São João University Hospital Center, Porto, Portugal between January $1^{\text {st }} 2007$ and December 31st 2018. Sociodemographic data, psychopathological variables and most probable diagnosis, based on ICD-10 criteria (WHO, 1992) were collected from their medical records. Psychotic symptoms were compared between three groups of patients:

Group 1 - Schizophrenia, Schizotypal Disorder, Schizoaffective Disorder and Non-Organic Non-Specific Psychosis;

Group 2 - Mental and behavioral disorders due to the use of cannabinoids, cocaine and multiple drugs:

Group 3 - Bipolar Disorder, Severe Depressive Episode with Psychotic Symptoms, Shared Psychotic Disorder and Acute Transien Psychotic Disorder

The sample included $\mathbf{2 3 9}$ patients, $\mathbf{1 8 5}$ males, with a mean age of $\mathbf{2 5 . 8}$ years $( \pm 5,70)$. The majority of patients were single $(\mathbf{n}=\mathbf{2 1 4})$, unemployed $(\mathbf{n = 1 0 7})$ and with a literacy between 6th to 12th grade $(\mathbf{n = 1 0 9})$. The most prevalent diagnosis was Mental and behavioral disorders due to the use of cannabinoids (F12, ICD-10) ( $\mathbf{n = 8 1}$, followed by Schizophrenia (F20, ICD-10) (n=56) and Non-Organic Non-Specific Psychosis (F29, ICD-10) $(\mathbf{n}=55)$.

There were some statistically significant differences $(p<0.05)$ between the three groups regarding prodromal symptoms of psychosis (graph 1$)$ such as insomnia, anxious mood, social isolation, suspicion, deterioration of overall functioning, unusual perceptual experiences, and bizarre thoughts/speech. These symptoms were more frequent in group 1.

Kurt Schneider's first-rank symptoms (third person auditory hallucinations, thought withdrawal, thought broadcasting, thought insertion, delusiona perception, passivity phenomena and somatic hallucinations) and negative symptoms (alogia, abulia and reduced affective display) were globally more prevalent in group 1 subjects, in comparison with the other two groups. A statistically significant difference $(p<0.05)$ was found on the following symptoms: third person auditory hallucinations, passivity phenomena, aboulia and reduced affect display.

A statistically significant difference $(\mathbf{p}<\mathbf{0 . 0 5})$ among all groups was found, concerning affective symptoms, in particular, dysphoria and mania which were more prevalent in individuals from group 2.

There was also a statistically significant difference $(p<0.05)$ between groups 1 and 2 regarding aggressiveness. This symptom was more prevalent in group 2 . There were no statistically significant differences $(p>0.05)$ between the groups concerning disorganized thought/speech.

Table 1: Sociodemographic data and diagnosis.

\begin{tabular}{|c|c|c|c|c|c|c|c|c|c|c|c|c|c|c|c|}
\hline \multicolumn{2}{|c|}{ Age (years) } & \multicolumn{2}{|c|}{ Gender (N) } & \multicolumn{2}{|c|}{$\begin{array}{c}\text { Marital } \\
\text { Status (N) }\end{array}$} & \multicolumn{2}{|c|}{ Work Status (N) } & \multicolumn{2}{|c|}{ Literacy (N) } & \multicolumn{6}{|c|}{ Diagnosis (N) } \\
\hline Mean & 25,8 & Masculine & 185 & Single & 214 & Unemployed & 107 & $<6^{\text {th }}$ grade & 32 & $\mathrm{~F} 12$ & 81 & F21 & 1 & F29 & 55 \\
\hline $\begin{array}{l}\text { Standard } \\
\text { Deviation }\end{array}$ & \pm 5.70 & Feminine & 54 & Married & 13 & Employed & 72 & $\begin{array}{l}6^{\text {th }}-12^{\text {th }} \\
\text { grade }\end{array}$ & 109 & F14 & 1 & F23 & 10 & F31 & 13 \\
\hline Minimum & 18 & & & Divorced & 11 & Student & 58 & College & 90 & F19 & 15 & F24 & 1 & F32.3 & 5 \\
\hline Maximum & 40 & & & Widower & 1 & Pensionist & 1 & Missing & 8 & F20 & 56 & F25 & 1 & & \\
\hline
\end{tabular}

Legend: F12 - Mental and behavioural disorders due to the use of cannabinoids; F14 - Mental and behavioural disorders due to the use of cocaine; F19 - Mental and behavioural disorders due to the use of other psychoactive substances; F20 - Schizophrenia; F21 - Schizotypal disorder; F23 - Acute psychotic and transient disorders; F24 - Acute and transient psychotic disorders; F25 - Schizoaffective disorders; F29 - Unspecified nonorganic psychosis; F31 -Bipolar affective disorder; F32.3 - Severe depressive episode with psychotic symptoms

Graph 1: Psychopathological comparison between groups

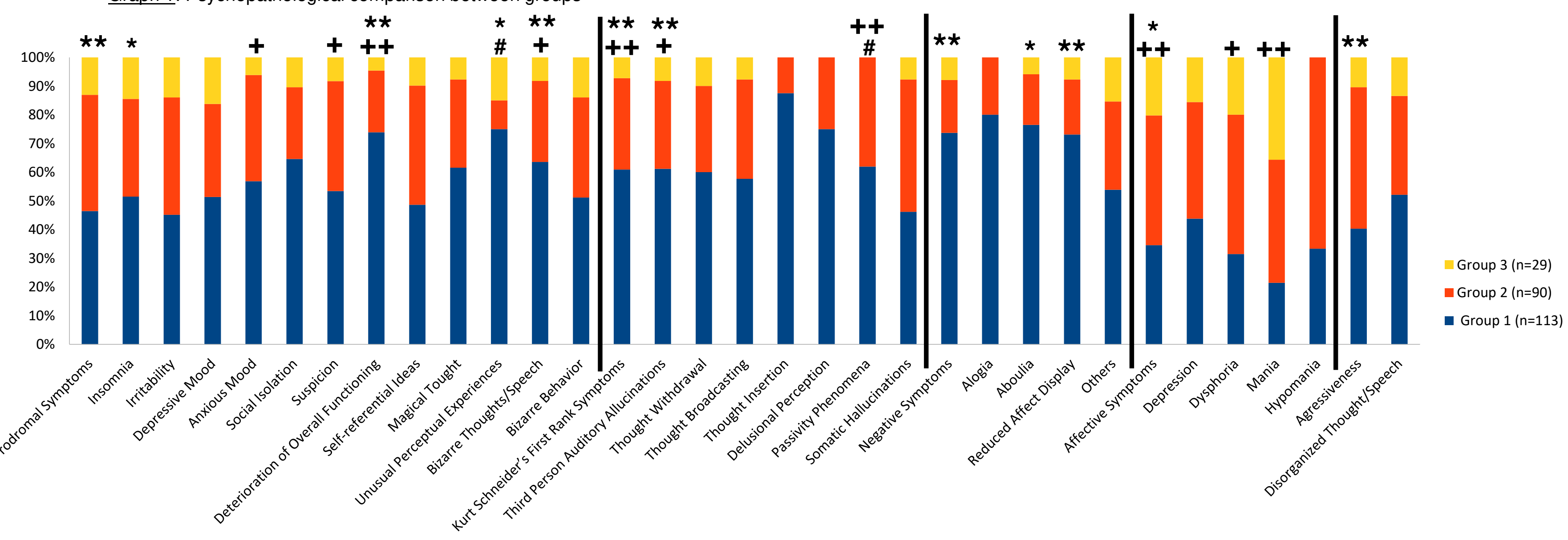

\section{Conclusion}

